\title{
Correlation of Uric Acid Levels and Parameters of Metabolic Syndrome
}

\author{
L. CIBIČKOVÁ ${ }^{1}$, K. LANGOVÁ ${ }^{2}$, H. VAVERKOVÁ ${ }^{1}$, V. KUBÍČKOVÁ ${ }^{3}$, D. KARÁSEK ${ }^{1}$ \\ ${ }^{1}$ Department of Internal Medicine III - Nephrology, Rheumatology and Endocrinology, Faculty of \\ Medicine and Dentistry, Palacky University, Olomouc, Czech Republic, ${ }^{2}$ Department of Medical \\ Biophysics, Faculty of Medicine and Dentistry, Palacky University, Olomouc, Czech Republic \\ ${ }^{3}$ Department of Clinical Biochemistry, University Hospital, Olomouc, Czech Republic
}

Received June 17, 2016

Accepted October 14, 2016

On-line February 28, 2017

\section{Summary}

Hyperuricemia has been described as associated with the risk of development metabolic syndrome; however the relationship between the uric acid level and particular parameters of metabolic syndrome remained unclear. We performed a cross-sectional study on a cohort of 833 dyslipidemic patients and correlated their levels of uric acid with parameters of insulin resistance, lipid metabolism, C-reactive protein, anthropometric parameters. We also defined patients with hypertriglyceridemic waist phenotype and compered their uric acid levels with those without this phenotype. We found that levels of uric acid are associated with parameters of metabolic syndrome. Specifically, dyslipidemia characteristic for metabolic syndrome (low HDL cholesterol and high triglycerides) correlates better with uric acid levels than parameters of insulin resistance. Also waist circumference correlates better with uric acid levels than body mass index. Patients with hypertriglyceridemic waist phenotype had higher levels of uric acid when compared with patients without this phenotype. Serum uric acid levels are even in low levels linearly correlated with parameters of metabolic syndrome (better with typical lipid characteristics than with parameters of insulin resistance) and could be associated with higher cardiovascular risk.

\section{Key words}

Metabolic syndrome • Uric acid • Hypertriglyceridemic waist • Lipid metabolism • Insulin resistance

\section{Corresponding author}

L'. Cibičková, Department of Internal Medicine III - Nephrology, Rheumatology and Endocrinology, University Hospital,
I.P. Pavlova 6, 77900 Olomouc, Czech Republic. Fax: +420 588442 526. E-mail: Cibickova@seznam.cz

\section{Introduction}

Metabolic syndrome has been defined as cluster of different cardiovascular risk factors, including visceral obesity, hypertension, dyslipidemia, and glucose intolerance. In 1999, the World Health Organization, proposed for the first time some diagnostic criteria for metabolic syndrome (Alberti et al. 1998). Afterward, the National Cholesterol Education Program's Adult Treatment Panel III (NCEP/ATP III) (Grundy et al. 2004) and the International Diabetes Federation (IDF) (Alberti et al. 2006) updated both metabolic syndrome diagnosis and definition. However, uric acid levels are not a part of any of provided metabolic syndrome definition, although the incidence of metabolic syndrome and hyperuricemia become higher (Tang et al. 2015, Sun et al. 2015). Whether hyperuricemia contributes to development of metabolic syndrome or is merely a by-product of other processes that cause this disorder has not been resolved. There are some experimental data providing evidence that hyperuricemia per se could have deleterious metabolic sequelae (DeBosh et al. 2015). Facchini et al. (1991) also demonstrated that pathophysiological mechanism responsible for this association is insulin resistance.

Recently, Carbone et al. (2013) have described the results from four longitudinal and 12 cross-sectional published studies (although these results could be subject 
to bias) regarding the association between uric acid levels and the metabolic syndrome risk. However, the strength and the consistency of the quantitative relationship between the uric acid level and metabolic syndrome remain unclear and inconclusive (Yuan et al. 2015).

To address this issue, we have performed a cross-sectional study on dyslipidemic patients to identify relationships between laboratory and anthropometric parameters connected to metabolic syndrome and uric acid levels.

\section{Methods}

\section{Study design and subjects}

The study was carried out as a cross sectional study on asymptomatic dyslipidemic subjects. 833 patients (402 men and 431 women) of the Lipid Center at the University Hospital Olomouc who came for their first visit because of hyperlipidemia (total cholesterol $\geq 5 \mathrm{mmol} / \mathrm{l}$ and/or triacylglycerols (TAG) $\geq 1.7 \mathrm{mmol} / \mathrm{l}$ ) between January 2005 and December 2015 were included in the study. Detailed medical history was obtained and physical examination performed. All subjects were tested for secondary hyperlipidemia, particularly diabetes mellitus, hypothyroidism, hepatic or renal failure. Exclusion criteria were as follows: lipid lowering therapy in previous 6 weeks, use of allopurinol, the presence of diabetes mellitus or other secondary hyperlipidemias, acute infection or trauma, acute cardiovascular event in the last 3 months, and heart failure NYHA III and IV. Patients were asked about their smoking cessation and divided into smokers (19.9\%) and non-smokers $(80.1 \%)$, whereas an ex-smoker was recorded as a non-smoker when he quit at a young age or had not smoked for a substantial time period - according to generally accepted definition (Králíková et al. 2015).

The study was reviewed and approved by the Institutional Ethics Committee of the Medical Faculty and University Hospital and informed consent was obtained from all participants.

\section{Anthropometric and laboratory measurements}

The waist circumference was measured in the standing position, at the middle point between the anterior iliac crest and the lower border of the ribs. The body mass index (BMI) was determined as body weight in $\mathrm{kg} /$ body height in $\mathrm{m}^{2}$. The hypertriglyceridemic waist phenotype was defined as waist $\geq 90 \mathrm{~cm}$ and $\mathrm{TAG} \geq 2.0 \mathrm{mmol} / 1$ in men and waist $\geq 85 \mathrm{~cm}$ and
$\mathrm{TAG} \geq 1.5 \mathrm{mmol} / \mathrm{l}$ in women (Arsenault et al. 2010).

\section{Biochemical analyses}

Venous blood samples were drawn after a $12 \mathrm{~h}$ of overnight fast. Total cholesterol (TC) concentrations were measured by enzymatic method CHOD-POD, standardized according to Abell-Kendall and ID/MS (set CHOL2, Roche Diagnostics GmbH, Mannheim, Germany). TAG results were obtained by enzymatic method GPO-POD, standardized according to ID/MS (set TRIGL, Roche Diagnostics GmbH, Mannheim, Germany). HDL-C was measured by enzymatic colorimetric test, standardized according to CDC reference method (set HDLC3, Diagnostics GmbH, Mannheim, Germany). LDL-C levels were calculated according to Friedewald formula. AIP (atherogenic index of plasma) was calculated as a log (TAG/HDL-C) (Frohlich et al. 2003) and non HDL-C as TC - HDL-C. Concentrations of apolipoprotein B (apoB) and apolipoprotein A1 (apoA1) were determined immunoturbidimetrically according to IFCC reference standards on COBASc8000 analyzer (sets APOBT and APOAT, all Roche Diagnostics GmbH, Mannheim, Germany). Glycemia was determined using the enzyme based Glucose hexokinase kit, standardized according to ID/MS (set GLUC3, Roche Diagnostics GmbH, Mannheim, Germany). C-reactive protein (hs-CRP) was assessed by means of an ultra-sensitive latex imunoturbidimetric method traceable to CRM 470 standard (set CRPL3, all Roche Diagnostics GmbH, Mannheim, Germany). Uric acid level was determined using enzymatic (uricase) colorimetric test standardized according to ID/MS (set UA2, Roche Diagnostics GmbH, Mannheim, Germany). All these assays were performed in a COBAS c8000 biochemical analyzer from Roche.

Insulin was determined using Insuline kit (Immunotech, Marseille, France) with specific antibodies by IRMA method. The result obtained were then used for calculation of HOMA-IR (homeostatis model assessment: fasting glycemia*fasting insulin/22.5) (Matthews et al. 1985). C-peptide was determined using the commercially available kit (Immunotech, Marseille, France) using specific anti-bodies by IRMA method.

\section{Statistical analyses}

Parameters with normal distribution, which was only patients' age (normality tested with Shapiro-Wilk test) were compared with Student's t-test and expressed as mean \pm standard deviation. Parameters with skewed distribution (BMI, waist circumference, total cholesterol, 
TAG, HDL-C, LDL-C, ApoB, glycemia, insulin, HOMA-IR, C-peptide, CRP, UA) were analyzed with Mann-Whitney U-tests and expressed as median (1st-3rd quartile). Spearman's correlation and partial correlation coefficient was used in order to determine the association among parameters of insulin resistance and lipid metabolism. Fisher's r-to-z transformation was applied to assess the significance of the difference between two correlation coefficients. Two paired t-test was used to compare patients with and without hypertriglyceridemic waist. Probability values of $p<0.05$ were considered statistically significant.

\section{Results}

The characteristics of the dyslipidemic subjects are summarized in Table 1 - both anthropometric and laboratory parameters are shown. Patients' age was $45.5 \pm 14.7$ years (mean \pm standard deviation). Other parameters had skewed distribution and are expressed as median $\left(1^{\text {st }}-3^{\text {rd }}\right.$ quartile $)$.

Table 1. Characteristics of the dyslipidemic subjects.

\begin{tabular}{|c|c|c|c|}
\hline & 1st quartile & Median & $\begin{array}{c}\text { 3rd } \\
\text { quartile }\end{array}$ \\
\hline$h s-C R P(m g / l)$ & 0.70 & 1.40 & 3.20 \\
\hline$T C(\mathrm{mmol} / \mathrm{l})$ & 5.20 & 6.30 & 7.40 \\
\hline$T A G(\mathrm{mmol} / \mathrm{l})$ & 1.20 & 1.70 & 2.70 \\
\hline $\begin{array}{l}A I P: \log \\
(T A G / H D L-C)\end{array}$ & -0.14 & 0.07 & 0.35 \\
\hline nonHDL (mmol/l) & 3.70 & 4.80 & 5.80 \\
\hline$H D L-C(\mathrm{mmol} / \mathrm{l})$ & 1.10 & 1.40 & 1.70 \\
\hline$L D L-C(\mathrm{mmol} / \mathrm{l})$ & 2.90 & 3.80 & 4.70 \\
\hline ApoAl $(g / l)$ & 1.34 & 1.52 & 1.74 \\
\hline$A p o B(g / l)$ & 0.95 & 1.14 & 1.39 \\
\hline $\begin{array}{l}\text { Uric acid levels } \\
(\mu \mathrm{mol} / \mathrm{l})\end{array}$ & 254.00 & 307.00 & 370.00 \\
\hline Glucose (mmol/l) & 4.60 & 5.00 & 5.50 \\
\hline Insulin (mIU/l) & 5.30 & 7.70 & 11.00 \\
\hline$H O M A-I R$ & 1.04 & 1.66 & 2.51 \\
\hline C-peptide (mg/l) & 1.60 & 2.30 & 3.30 \\
\hline$B M I\left(\mathrm{~kg} / \mathrm{m}^{2}\right)$ & 23.10 & 25.70 & 28.60 \\
\hline $\begin{array}{l}\text { Waist circumference } \\
(\mathrm{cm})\end{array}$ & 78.00 & 88.00 & 97.00 \\
\hline
\end{tabular}

Correlation between uric acid levels and lipid parameters, markers of insulin resistance and anthropometric parameters are displayed in Table 2.

Markers of lipid metabolism showed moderate correlations (correlation coefficient $r=0.4-0.6$ ) with uric acid levels (positive correlation with TAG and AIP and negative with HDL cholesterol) whereas parameters of insulin resistance (glycemia, insulin, C-peptide, HOMA-IR) demonstrated only low positive correlations (correlation coefficient $\mathrm{r}=0.1-0.3$ ) with uric acid levels. In our study, we have not found any significant differences between smokers and non-smokers regarding correlations with uric acid levels.

Both studied anthropometric parameters - BMI and waist circumference - proved moderate correlations with uric acid levels, but the correlation was stronger with waist circumference $(r=0.535)$ than with BMI $(r=0.422)$ and the difference was statistically significant $(\mathrm{p}=0.005)$.

We have selected patients with hypertriglyceridemic waist phenotype (as defined by Arsenault et al. 2010) and compared them with those without it. Patients with hypertriglyceridemic waist $(n=218)$ had significantly higher levels of uric acid when compared with patients without hypertriglyceridemic $(\mathrm{n}=488)$ waist $(\mathrm{p}<0.0001)$ as shown in Figure 1.

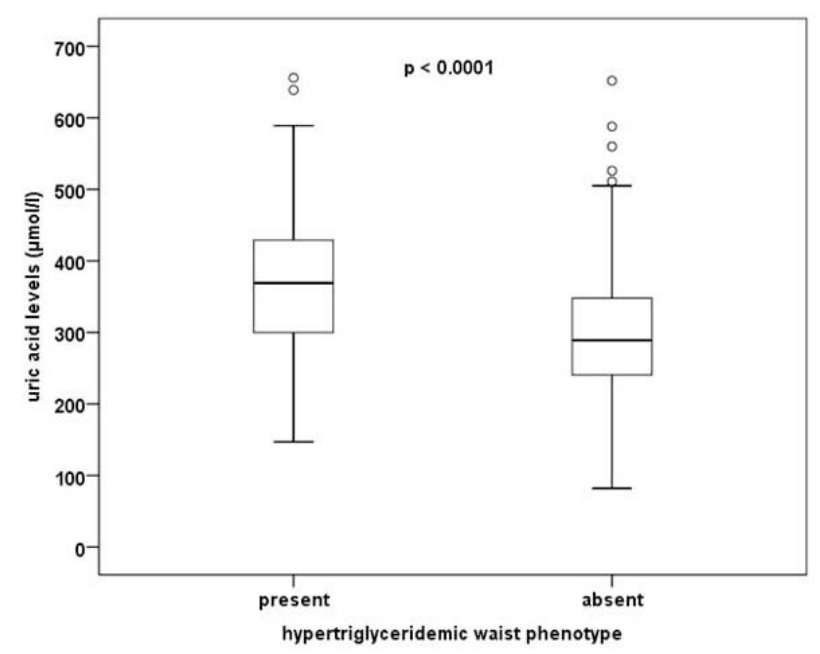

Fig. 1. Patients with/without hypertriglyceridemic waist phenotype and their correlation with uric acid levels.

Multiple linear regressions with stepwise elimination procedure were used to select significant predictors for uric acid levels. The model includes only those predictors whose contribution to the predicted variance (uric acid level) was statistically significant. Waist circumference, HDL cholesterol, C-peptide and insulin were found to be significant predictors of uric acid levels and are shown in Table 3. 
Table 2. Correlation between uric acid levels and lipid parameters, markers of insulin resistance and anthropometric parameters. Spearman's correlation coefficient for the whole group and separately for non-smokers and smokers. Bonefoni correction for multiple testing was used.

\begin{tabular}{|c|c|c|c|c|c|}
\hline \multicolumn{3}{|c|}{ Correlation with uric acid levels } & \multirow{2}{*}{$\begin{array}{c}\text { Whole group } \\
0.109\end{array}$} & \multirow{2}{*}{$\begin{array}{c}\text { Non-smokers } \\
0.115\end{array}$} & \multirow{2}{*}{$\begin{array}{c}\text { Smokers } \\
0.127\end{array}$} \\
\hline \multirow{32}{*}{ Spearman's rho } & Age & Correlation Coefficient & & & \\
\hline & \multirow{3}{*}{ hs-CRP } & $p$ & 0.046 & 0.088 & 1.000 \\
\hline & & Correlation Coefficient & 0.134 & 0.136 & 0.153 \\
\hline & & $p$ & 0.005 & 0.020 & 1.000 \\
\hline & \multirow{2}{*}{ Total cholesterol } & Correlation Coefficient & 0.085 & 0.053 & 0.118 \\
\hline & & $p$ & 0.236 & 1.000 & 1.000 \\
\hline & \multirow{2}{*}{ TAG } & Correlation Coefficient & 0.442 & 0.412 & 0.453 \\
\hline & & $p$ & $<0.0001$ & $<0.0001$ & $<0.0001$ \\
\hline & \multirow{2}{*}{ AIP } & Correlation Coefficient & 0.478 & 0.471 & 0.445 \\
\hline & & $p$ & $<0.0001$ & $<0.0001$ & $<0.0001$ \\
\hline & \multirow{2}{*}{ nonHDL } & Correlation Coefficient & 0.200 & 0.178 & 0.190 \\
\hline & & $p$ & $<0.0001$ & 0.0001 & 0.255 \\
\hline & \multirow{2}{*}{ HDL cholesterol } & Correlation Coefficient & -0.403 & -0.409 & -0.324 \\
\hline & & $p$ & $<0.0001$ & $<0.0001$ & 0.0004 \\
\hline & \multirow{2}{*}{ LDL cholesterol } & Correlation Coefficient & -0.029 & -0.010 & -0.136 \\
\hline & & $p$ & 1.000 & 1.000 & 1.000 \\
\hline & \multirow{2}{*}{ ApoA1 } & Correlation Coefficient & -0.312 & -0.319 & -0.269 \\
\hline & & $p$ & $<0.0001$ & $<0.0001$ & 0.019 \\
\hline & \multirow{2}{*}{ ApoB } & Correlation Coefficient & 0.126 & 0.114 & 0.096 \\
\hline & & $p$ & 0.005 & 0.063 & 1.000 \\
\hline & \multirow{2}{*}{ Glucose } & Correlation Coefficient & 0.273 & 0.272 & 0.240 \\
\hline & & $p$ & $<0.0001$ & $<0.0001$ & 0.034 \\
\hline & \multirow{2}{*}{ Insulin } & Correlation Coefficient & 0.174 & 0.177 & 0.187 \\
\hline & & $p$ & $<0.0001$ & 0.0002 & 0.380 \\
\hline & \multirow{2}{*}{ HOMA } & Correlation Coefficient & 0.182 & 0.196 & 0.146 \\
\hline & & $p$ & $<0.0001$ & $<0.0001$ & 1.000 \\
\hline & \multirow{2}{*}{ C-peptide } & Correlation Coefficient & 0.307 & 0.312 & 0.244 \\
\hline & & $p$ & $<0.0001$ & $<0.0001$ & 0.047 \\
\hline & \multirow{2}{*}{ BMI } & Correlation Coefficient & 0.422 & 0.441 & 0.370 \\
\hline & & $p$ & $<0.0001$ & $<0.0001$ & $<0.0001$ \\
\hline & \multirow{2}{*}{$\begin{array}{c}\text { Waist } \\
\text { circumference }\end{array}$} & Correlation Coefficient & 0.535 & 0.544 & 0.481 \\
\hline & & $p$ & $<0.0001$ & $<0.0001$ & $<0.0001$ \\
\hline
\end{tabular}

Table 3. Multiple linear regressions with stepwise elimination procedure for waist circumference, HDL cholesterol, C-peptide and insulin.

\begin{tabular}{|c|c|c|c|c|c|}
\hline & \multicolumn{2}{|c|}{ Unstandardized Coefficients } & \multirow{2}{*}{$\begin{array}{c}\text { Standardized Coefficients } \\
\text { Beta }\end{array}$} & \multirow[b]{2}{*}{$\mathbf{t}$} & \multirow{2}{*}{ Sig } \\
\hline & B & Std. Error & & & \\
\hline Constant & 78.526 & 28.431 & & 2.762 & 0.0060 \\
\hline Waist circumference & 2.968 & 0.278 & 0.434 & 10.679 & $<0.0001$ \\
\hline HDL cholesterol & -26.736 & 7.267 & -0.138 & -3.679 & 0.0003 \\
\hline C-peptide & 16.418 & 3.546 & 0.218 & 4.630 & $<0.0001$ \\
\hline Insulin & -2.602 & 0.754 & -0.155 & -3.453 & 0.0006 \\
\hline
\end{tabular}




\section{Discussion}

In this cross-sectional study on a cohort of dyslipidemic patients, we found that levels of uric acid were associated with parameters of metabolic syndrome. Specifically, dyslipidemia characteristic for metabolic syndrome (low HDL cholesterol and high TAG) correlates better with uric acid levels than parameters of insulin resistance. Also atherogenic index of plasma (AIP) proved correlations with uric acid levels. This parameter correlates well with parameters of insulin resistance (Cibickova et al. 2014). AIP is taking into account not only HDL cholesterol levels but also plasma TAG, that play the role of a regulator of lipoprotein interactions and not the role of an independent risk marker. High TAG and low HDL-C concentrations induce both an increase in small HDL particle and an increase in small, dense LDL particles (Dobiasova 2004), which is especially important in patients with metabolic syndrome. Our data provide confirmation of recent findings on relationship between serum uric acid and metabolic syndrome, as summarized and quantified by Yuan et al. - they have found significant positive linear relationship between serum uric acid levels and the risk of metabolic syndrome in a meta-analysis of prospective studies (Yuan et al. 2015).

The underlying cause of metabolic syndrome is visceral obesity, which can be measured by waist circumference. Several lines of evidence, both epidemiologic and clinical, point to a close interrelation between hyperuricemia and obesity - for example Masuo et al. (2003) have demonstrated that serum uric acid concentrations predict subsequent weight gain. Sautin et al. (2007) suggest that hyperuricemia induces redox-dependent signaling and oxidative stress in adipocytes. Since oxidative stress in the adipose tissue has recently been recognized as a major cause of insulin resistance and cardiovascular disease, hyperuricemia-induced alterations in oxidative homeostasis in the adipose tissue might play an important role in these derangements (Sautin et al. 2007). In agreement with other authors (Guerra 2015, Ciarla et al. 2015) we found positive correlation of uric acid levels with waist circumference. Moreover, waist circumference correlated better with uric acid levels than BMI. Our study provides support for importance of measurement waist circumference rather than only assessing BMI. He has newly found out, that also patients with hypertriglyceridemic waist phenotype had higher levels of uric acid. This finding is in agreement with Arsenault et al. (2010), who proposed assessing of hypertriglyceridemic waist phenotype as a combination of increased waist circumference and hypertriglyceridemia. It has been proposed as an inexpensive approach to identify patients with excess intra-abdominal adiposity and associated metabolic abnormalities and was associated with a deteriorated cardiometabolic risk profile and an increased risk for coronary artery disease (Arsenault et al. 2010).

In contrast to lipid and anthropometric parameters of metabolic syndrome, the relationship between uric acid levels and parameters of insulin resistance and diabetes are not clearly established yet. We have also found only weak correlations of parameters of insulin resistance (glycemia, insulin, C-peptide, HOMA-IR) with uric acid levels. Also the biological mechanisms underlying the association between serum uric acid levels and development of diabetes remain a matter of debate. Hyperuricemia may lead to endothelial dysfunction and nitric oxide inhibition, which in turn contribute to insulin resistance and thus, diabetes (Nakagawa et al. 2005). This is supported by experimental findings that showed how fructose-induced hyperuricemia in rats leads to insulin resistance along with components of metabolic syndrome, and how these conditions are improved by decreasing uric acid levels (Nakagawa et al. 2005, Hallfrish 1990). Magnitude of insulin resistance and serum uric acid concentration were significantly related in healthy, nondiabetic, individuals (Facchini et al. 1991). Prospective data from 2 generations of the Framingham Heart Study provide evidence that individuals with higher serum uric acid, including younger adults, are at a higher future risk of type 2 diabetes independent of other known risk factors (Bhole et al. 2010). These data were confirmed by a 15-year follow-up which found higher incidence rates of diabetes and prediabetes among persons with greater serum urate concentrations (Kirshan et al. 2012). On the other hand, in a shorter 10-year longitudinal study in adolescents, uric acid levels did not affect the occurrence of type 2 diabetes in both genders (Sun et al. 2015). In a smaller study, Ciara et al. (2015) showed that even low levels of uric acid were linearly correlated with BMI, waist circumference, glucose and insulin levels, triglycerides and hs-CRP levels. On a larger group of patients we have confirmed these data whereas median of uric acid levels in our study was also in normal range.

Besides of lipid parameters and parameters of 
insulin resistance we have also studied relationship of uric acid levels to hs-CRP. CRP, as a hepatic biomarker associated with metabolic syndrome might be particularly useful to better manage and prevent the atherothrombotic risk (Carbone et al. 2013).

One pathophysiological model proposes that the oxidative stress associated with hyperuricemia leads to lipid oxidation that in turn becomes antigenic, triggering an immune response and systemic vascular inflammation (Kanellis et al. 2005). A recent study on 80 patients with acute coronary syndrome and on 36 healthy individuals showed correlation between hs-CRP and uric acid levels which indicates a possible role of uric acid as a marker of low-grade inflammation and its potential in risk assessment in cardiovascular diseases (Spahic et al. 2015). Another smaller study on patients with metabolic syndrome demonstrated that hs-CRP and serum uric acid are associated with metabolic syndrome components and the combined rise of hs-CRP and uric acid is associated with the increase in severity of metabolic syndrome (Sah et al. 2016). In our study on a larger cohort of dyslipidemic patients we observed association of hs-CRP with serum uric acid level which is similar to above mentioned studies.

We have studied relationship between uric acid levels and blood pressure, which is one of the main risk factors of metabolic syndrome. Although blood pressure was measured in all patients, it has been often influenced by various antihypertensive drugs and that is why we have decided not to analyze it.

In summary, this study supports relationship between serum urate concentration and parameters of metabolic syndrome. Specifically, dyslipidemia characteristic for metabolic syndrome (low HDL cholesterol and high triglycerides, AIP) correlates better with uric acid levels than parameters of insulin resistance. Also waist circumference correlates better with uric acid levels than BMI. Patients with hypertriglyceridemic waist phenotype had higher levels of uric acid when compared with patients without this phenotype. Moreover we have found linear association of uric acid levels and hs-CRP. Therefore, increasing serum uric acid levels could be associated with higher cardiovascular risk.

\section{Conflict of Interest}

There is no conflict of interest.

\section{Acknowledgements}

Supported by MH CZ - DRO (FNO1, 00098892) and IGA-LF-2016-014.

\section{References}

ALBERTI KG, ZIMMET PZ: Definition, diagnosis and classification of diabetes mellitus and its complications. Part 1: diagnosis and classification of diabetes mellitus provisional report of a WHO consultation. Diabet Med 15: 539-553, 1998.

ALBERTI KG, ZIMMET P, SHAW J: Metabolic syndrome--a new world-wide definition. A consensus statement from the International Diabetes Federation. Diabet Med 23: 469-480, 2006.

ARSENAULT BJ, LEMIEUX I, DESPRÉS JP, WAREHAM NJ, KASTELEIN JJ, KHAW KT, BOEKHOLT SM: The hypertriglyceridemic-waist phenotype and the risk of coronary artery disease: results from the EPIC-Norfolk prospective population study. CMAJ 182: 1427-1432, 2010.

BHOLE V, CHOI JW, KIM SW, DE VERA M, CHOI H: Serum uric acid levels ant the risk of type 2 diabetes: a prospective study. Am J Med 123: 957-961, 2010.

CARBONE F, MONTECUCCO F, MACH F, PONTREMOLI R, VIAZZI F: The liver and the kidney: Two critical organs influencing the atherothrombotic risk in metabolic syndrome. Thromb Haemost 110: 940-958, 2013.

CIARLA S, GIORGINI P, STRUGLIA M, STRIULI R, NECOZIONE S, DESIDERI G, PROPERZI G, FERRI C: Associations between low levels of serum uric acid and cardiometabolic parameters. Arch Physiol Biochem 121: 139-143, 2015.

CIBIČKOVÁ L, KARÁSEK D, LANGOVÁ K, VAVERKOVÁ H, ORSÁG J, LUKEŠ J, NOVOTNÝ D: Correlation of lipid parameters and markers of insulin resistance: does smoking make a difference? Phys Res 63: 387-394, 2014.

DEBOSH BJ, KLUTH O, FUJIWARA H, SCHURMANN A, MOLAY K: Early-onset metabolic syndrome in mice lacking the intestinal uric acid transporter SLC2A9. Nat Commun 5: 4642, 2014. 
DOBIASOVA M: Atherogenic index of plasma (log (TAG/HDL-cholesterol): theoretical and practical implications. Editorial. Clin Chem 50: 1113-1115, 2004.

FACCHINI F, CHEN YD, HOLLENBECK CB, REAVEN GM: Relationship between resistance to insulin-mediated glucose uptake, urinary uric acid clearance, and plasma uric acid concentration. JAMA 266: 3008-3011, 1991.

GRUNDY SM, BREWER HB JR, CLEEMAN JI, SMITH SC JR, LENFANT C: Definition of metabolic syndrome: Report of the National Heart, Lung, and Blood Institute/American Heart Association conference on scientific issues related to definition. Circulation 109: 433-438, 2004.

RUBIO-GUERRA AF, MORALES-LÓPEZ H, GARRO-ALMENDARO AK, VARGAS-AYALA G, DURÁNSALGADO MB, HUERTA-RAMÍREZ S, LOZANO-NUEVO JJ: Circulating levels of uric acid and risk for metabolic syndrome. Curr Diabetes Rev 13: 87-90, 2017.

HALLFRISH J: Metabolic effects of dietary fructose. FASEB J 4: 2652-2660, 1990.

KANELLIS J, KANG DH: Uric acid as a mediator of endothelial dysfunction, inflammation, and vascular disease. Semin Nephrol 25: 39-42, 2005.

KRÁLÍKOVÁ E, ČEŠKA R, PÁNKOVÁ A, ŠTĚPÁNKOVÁ L, ZVOLSKÁ K, FELBROVÁ V, KULOVANÁ S, ZVOLSKÝ M: Tobacco dependence treatment guidelines. (In Czech) Vnitr Lek 61 (Suppl 1): 1S4-1S15, 2015.

KRISHNAN E, PANDYA BJ, CHUNG L, HARIRI A, DABBOUS O: Hyperuricemia in young adults and risk of insulin resistance, prediabetes, and diabetes: a 15-year follow-up study. Am J Epidemiol 176: 108-116, 2012.

MATTHEWE DR, HOSKER JP, RUDENSKI AS, NAYLOR BA, TREACHER DF, TURNER RC: Homeostasis model assessment: insulin resistance and beta-cell function from fasting plasma glucose and insulin concentrations in man. Diabetologia 28: 412-419, 1985.

MASUO K, KAWAGUCHI H, MIKAMI H, OGIHARA T, TUCK ML: Serum uric acid and plasma norepinephrine concentrations predict subsequent weight gain and blood pressure elevation. Hypertension 42: 474-480, 2003.

NAKAGAWA T, TUTTLE KR, SHORT RA, JOHNSON RJ: Hypothesis: fructose-induced hyperuricemia as a causal mechanism for the epidemic of the metabolic syndrome. Nat Clin Pract Nephrol 1: 80-86, 2005.

SAUTIN YY, NAKAGAWA T, ZHARIKOV S, JOHNSON RJ: Adverse effects of the classic antioxidant uric acid in adipocytes: NADPH oxidase-mediated oxidative/nitrosative stress. Am J Physiol Cell Physiol 293: C584-C596, 2007.

SPAHIĆ E, HASIĆ S, KISELJAKOVIĆ E, RESIĆ H, KULIĆ M: Positive correlation between uric acid and C-reactive protein serum level in healthy individuals and patients with acute coronary syndromes. Med Glas (Zenica) 12: 128-132, 2015.

SUN HL, PEI D, LUE KH, CHEN YL: Uric acid levels can predict metabolic syndrome and hypertension in adolescents: a 10-year longitudinal study. PLoS One 10: e0143786, 2015.

TANG L, KUBOTA M, NAGAI A, MAMEMOTO K, TOKUDA M: Hyperurikemia in obese children and adolescents: the relationship with metabolic syndrome. Pediatr Rep 2: e12, 2010.

YUAN H, YU C, LI X, SUN L, ZHU X, ZHAO C, ZHANG Z, YANG Z: Serum uric acid levels and risk of metabolic syndrome: a dose-response meta-analysis of prospective studies. J Clin Endocrinol Metab 100: 4198-4207, 2015. 